\title{
UNIFORM BOUNDEDNESS IN METRIC SPACES ${ }^{1}$
}

JAMES D. STEIN, JR.

\begin{abstract}
Let $(X, d),\left(Y, d^{\prime}\right)$ be metric spaces, $\mathscr{F}$ a family of maps from $X$ into $Y$. Let $x_{0} \in X . \mathscr{F}$ is said to be pointwise-bounded if for each $x \in X, \sup \left\{d^{\prime}\left(T x, T x_{0}\right) \mid T \in \mathscr{F}\right\}$ is finite, and is uniformly bounded if for each $p>0, \sup \left\{d^{\prime}\left(T x, T x_{0}\right) \mid T \in \mathscr{F}, d\left(x, x_{0}\right) \leqq p\right\}$ is finite. The major result of this paper is to place a sufficient condition on the maps in $\mathscr{F}$ to ensure that, if $X$ is complete, a pointwisebounded family of continuous maps is uniformly bounded, and to show that this result is best possible.
\end{abstract}

The object of this paper is to present a general theorem in which uniform boundedness is a consequence of pointwise-boundedness. The technique used is the abstract nonlinear form of the gliding hump method first employed by Lebesgue and Toeplitz. An attractive linear application of this argument can be found in the paper of V. Ptak referred to in the bibliography.

The following definition, though somewhat awkward in appearance, is crucial to the development of the theory.

Definition 1. Let $(X, d),\left(Y, d^{\prime}\right)$ be metric spaces, $T: X \rightarrow Y$. Let $x, y \in X$ be such that $T x \neq T y$. If $0<\alpha<1$, define

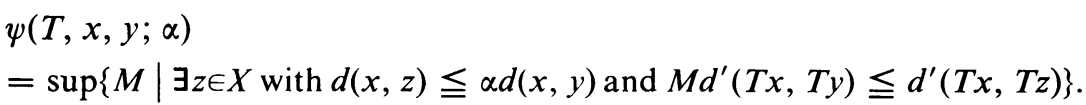

If there is no such $z$, define $\psi(T, x, y ; \alpha)=0$.

Note that $\psi(T, x, y ; \alpha) \geqq 0$, and if $0 \leqq M<\psi(T, x, y ; \alpha)$, then there is a $z \in X$ with $d(x, z) \leqq \alpha d(x, y)$ and $d^{\prime}(T x, T z) \geqq M d^{\prime}(T x, T y)$.

Definition 2. Let $(X, d),\left(Y, d^{\prime}\right)$ be metric spaces, $\mathscr{F}$ a family of maps from $X$ into $Y$. If $x, y \in X$, define $\psi(x, y ; \alpha)=\inf \{\psi(T, x, y ; \alpha) \mid T \in \mathscr{F}, T x \neq T y\}$ for $0<\alpha<1$. Finally, if $0<\alpha<1$, let $\kappa(\alpha)=\inf \{\psi(x, y ; \alpha) \mid x \neq y\}$.

We come now to the major result of this paper.

Presented to the Society, April 10, 1971; received by the editors January 20, 1971. AMS 1970 subject classifications. Primary 54E50.

Key words and phrases. Uniform boundedness.

${ }^{1}$ The preparation of this paper was supported in part by NSF Grant GP-11475.

(c) American Mathematical Society 1972 
THEOREM 1. Let $X$ be a complete metric space, $Y$ a metric space. Let $\mathscr{F}$ be a pointwise-bounded family of continuous maps from $X$ into $Y$, and let $\kappa(\alpha)>0$ for each $\alpha \in(0,1)$. Then $\mathscr{F}$ is uniformly bounded.

Proof. Let $x_{0} \in X$, and let $p<0$. Assume that the theorem is false. We then assert that we can prove the following: given $T_{1}, \cdots, T_{n} \in \mathscr{F}$, $x_{1}, \cdots, x_{n} \in X$ with $d\left(x_{0}, x_{k}\right)<p(1 \leqq k \leqq n)$, and $M>0$, then we can find an $x_{n+1} \in X$ and $T_{n+1} \in \mathscr{F}$ with $d\left(x_{0}, x_{n+1}\right)<p, d\left(x_{n}, x_{n+1}\right)<1 / 2^{n+1}$,

$$
d^{\prime}\left(T_{n+1} x_{n+1}, T_{n+1} x_{0}\right)>M, \text { and } d^{\prime}\left(T_{k} x_{n}, T_{k} x_{n+1}\right)<1 / 2^{n+1}
$$

for $1 \leqq k \leqq n$. To prove this assertion, let $S(x)=\sup \left\{d^{\prime}\left(T x, T x_{0}\right) \mid T \in \mathscr{F}\right\}$, and assume $M>0, x_{1}, \cdots, x_{n} \in X$, and $T_{1}, \cdots, T_{n} \in \mathscr{F}$ are given as above. If the theorem is false, $\mathscr{F}$ is not uniformly bounded on the sphere of radius $p$ and center $x_{0}$, so given $K>0$ there is a $z \in X$ and $T \in \mathscr{F}$ with $d\left(x_{0}, z\right)<p$ and $K<d^{\prime}\left(T x_{0}, T z\right)$. Consequently

$$
K<d^{\prime}\left(T x_{0}, T z\right) \leqq d^{\prime}\left(T x_{0}, T x_{n}\right)+d^{\prime}\left(T x_{n}, T z\right) \leqq S\left(x_{n}\right)+d^{\prime}\left(T x_{n}, T z\right) .
$$

So we can always find a $T \in \mathscr{F}, z \in X$ with $d\left(x_{0}, z\right)<p$ and $d^{\prime}\left(T x_{n}, T z\right)$ arbitrarily large.

Since $T_{1}, \cdots, T_{n}$ are continuous at $x_{n}$, choose $\delta_{k}(1 \leqq k \leqq n)$ such that $x \in X, d\left(x, x_{n}\right)<\delta_{k} \Rightarrow d^{\prime}\left(T_{k} x, T_{k} x_{n}\right)<1 / 2^{n+1}$. Now define

$$
\alpha=\frac{1}{3} \min \left(1 / 2^{n+1} p, \delta_{1} / 2 p, \cdots, \delta_{n} / 2 p,\left(p-d\left(x_{0}, x_{n}\right)\right) / p\right),
$$

then $0<\alpha<1$. Define $\mu(\alpha)=\frac{1}{2} \kappa(\alpha)$ if $\kappa(\alpha)$ is finite, and $\mu(\alpha)=1$ otherwise. Now choose $y \in X, T\left(=T_{n+1}\right) \in \mathscr{F}$ with $d\left(x_{0}, y\right)<p, \mu(\alpha) d^{\prime}\left(T x_{n}, T_{y}\right)>$ $M+S\left(x_{n}\right)$. Since $\mu(\alpha)<\kappa(\alpha)$, choose $x_{n+1} \in X$ with $d\left(x_{n}, x_{n+1}\right) \leqq \alpha d\left(x_{n}, y\right)$ and $d^{\prime}\left(T x_{n}, T x_{n+1}\right) \geqq \mu(\alpha) d^{\prime}\left(T x_{n}, T y\right)$. We now make the following observations:

(1) $d\left(x_{n}, x_{n+1}\right) \leqq \alpha d\left(x_{n}, y\right) \leqq 2 p \alpha<1 / 2^{n+1}$.

(2) if $1 \leqq k \leqq n, d^{\prime}\left(T_{k} x_{n}, T_{k} x_{n+1}\right)<1 / 2^{n+1}$, since $d\left(x_{n}, x_{n+1}\right) \leqq 2 p \alpha<\delta_{k}$.

(3) $d\left(x_{0}, x_{n+1}\right) \leqq d\left(x_{0}, x_{n}\right)+d\left(x_{n}, x_{n+1}\right) \leqq d\left(x_{0}, x_{n}\right)+2 p \alpha<p$.

(4) $\mu(\alpha) d^{\prime}\left(T x_{n}, T y\right) \leqq d^{\prime}\left(T x_{n}, T x_{n+1}\right) \leqq d^{\prime}\left(T x_{n}, T x_{0}\right)+d^{\prime}\left(T x_{0}, T x_{n+1}\right) \leqq$ $S\left(x_{n}\right)+d^{\prime}\left(T x_{0}, T x_{n+1}\right) \Rightarrow d^{\prime}\left(T x_{0}, T x_{n+1}\right) \geqq \mu(\alpha) d^{\prime}\left(T x_{n}, T y\right)-S\left(x_{n}\right)>M$.

This completes the proof of the assertion.

We now use the assertion just established to set up an induction. Since $\mathscr{F}$ is not uniformly bounded, we can find $x_{1} \in X, T_{1} \in \mathscr{F}$ with $d^{\prime}\left(T_{1} x_{0}, T_{1} x_{1}\right)>$ 2. Having chosen $x_{1}, \cdots, x_{n} \in X$, with $d\left(x_{0}, x_{k}\right)<p$ for $1 \leqq k \leqq n$, and $T_{1}, \cdots, T_{n} \in \mathscr{F}$, choose $x_{n+1} \in X, T_{n+1} \in \mathscr{F}$ with $d\left(x_{0}, x_{n+1}\right)<p, d\left(x_{n}, x_{n+1}\right)<$ $1 / 2^{n+1}, d^{\prime}\left(T_{n+1} x_{0}, T_{n+1} x_{n+1}\right)>n+2$, and $d^{\prime}\left(T_{k} x_{n}, T_{k} x_{n+1}\right)<1 / 2^{n+1}$ for $1 \leqq k \leqq n$. Clearly $\left\{x_{n} \mid n=1,2, \cdots\right\}$ is Cauchy; by completeness there is an $x \in X$ with $x_{n} \rightarrow x$. Clearly $d\left(x_{0}, x\right) \leqq p$. Since $T_{n}$ is continuous, we see that

$$
\lim _{m \rightarrow \infty} d^{\prime}\left(T_{n} x, T_{n} x_{m+1}\right)=0 .
$$


So

$$
\begin{aligned}
d^{\prime}\left(T_{n} x_{0}, T_{n} x_{n}\right) & \leqq d^{\prime}\left(T_{n} x_{0}, T_{n} x\right)+d^{\prime}\left(T_{n} x, T_{n} x_{n}\right) \\
& \leqq \cdots \leqq d^{\prime}\left(T_{n} x_{0}, T_{n} x\right)+\sum_{k=n}^{m} d^{\prime}\left(T_{n} x_{k}, T_{n} x_{k+1}\right)+d^{\prime}\left(T_{n} x, T_{n} x_{m+1}\right)
\end{aligned}
$$

as $m \rightarrow \infty$ we obtain

$$
\begin{aligned}
d^{\prime}\left(T_{n} x_{0}, T_{n} x_{n}\right) & \leqq d^{\prime}\left(T_{n} x_{0}, T_{n} x\right)+\sum_{k=n}^{\infty} d^{\prime}\left(T_{n} x_{k}, T_{n} x_{k+1}\right) \\
& <d^{\prime}\left(T_{n} x_{0}, T_{n} x\right)+\sum_{k=n}^{\infty} 2^{-k-1} \\
& <d^{\prime}\left(T_{n} x_{0}, T_{n} x\right)+1
\end{aligned}
$$

since $k \geqq n \Rightarrow d^{\prime}\left(T_{n} x_{k}, T_{n} x_{k+1}\right)<2^{-k-1}$. So

$$
n+1<d^{\prime}\left(T_{n} x_{0}, T_{n} x_{n}\right)<d^{\prime}\left(T_{n} x_{0}, T_{n} x\right)+1 \Rightarrow d^{\prime}\left(T_{n} x_{0}, T_{n} x\right)>n,
$$

contradicting the pointwise-boundedness of $\mathscr{F}$. Q.E.D.

It is somewhat surprising that this result is best possible, in that it is impossible to weaken the condition that $\kappa(\alpha)>0$ for $0<\alpha<1$, as the following example will indicate.

EXAmPLE 1. Let $X=[0,1], Y=R$. If $n \geqq 2$, define

$$
\begin{aligned}
T_{n}(x) & =2 n^{2} x, & 0 \leqq x \leqq 1 / 2 n, \\
& =2 n(1-n) x+2 n-1, & 1 / 2 n \leqq x \leqq 1 / n, \\
& =(n /(1-n))(x-1), & 1 / n \leqq x \leqq 1 .
\end{aligned}
$$

Each $T_{n}$ is continuous, the family is pointwise-bounded (if $x>0$, choose $N$ with $x>1 / N$, then $\left.n \geqq N \Rightarrow T_{n}(x) \leqq 1\right)$, but the family is not uniformly bounded, as $T_{n}(1 / 2 n)=n$.

We now compute $\psi\left(T_{n}, 1,1 / 2 n ; \frac{1}{2}\right)$. Since $(1+2 n) / 4 n$ is the midpoint of $[1 / 2 n, 1]$, we have $T_{n}((1+2 n) / 4 n)=(2 n-1) / 4(n-1)$, and so $\psi\left(T_{n}, 1,1 / 2 n ; \frac{1}{2}\right)=(2 n-1) / 4 n(n-1) ;$ since $\kappa\left(\frac{1}{2}\right) \leqq(2 n-1) / 4 n(n-1)$ we see that $\kappa\left(\frac{1}{2}\right)=0$. However, if $x \neq y$, we can show that $\psi(x, y ; \alpha)>0$ for $0<\alpha<1$. Assume $x<y$, if $1 / N<x$ then, for $n \geqq N, T_{n}$ is linear on $[x, y]$, and so $n \geqq N \Rightarrow \psi\left(T_{n}, x, y ; \alpha\right)=\alpha$. Since

$$
\psi(x, y ; \alpha)=\min \left(\alpha, \psi\left(T_{1}, x, y ; \alpha\right), \cdots, \psi\left(T_{n}, x, y ; \alpha\right)\right)
$$

(actually only those $k(1 \leqq k \leqq n)$ for which $T_{k} x \neq T_{k} y$ are included in the minimum), $\psi(x, y ; \alpha)>0$. This example shows that it is impossible to weaken the condition $\kappa(\alpha)>0$ in Theorem 1 . 
For a family of linear maps on a Banach space, uniform boundedness is equivalent to equicontinuity. This is not the case in general, as can be seen from the following example.

EXAmple 2 . Define $\varphi:[0,1] \rightarrow R$ by $\varphi(x)=2 x$ if $0 \leqq x \leqq \frac{1}{2}, \varphi(x)=$ $2(1-x)$ if $\frac{1}{2} \leqq x \leqq 1$. Extend $\varphi$ to $R$ by making $\varphi(x+1)=\varphi(x), \forall x \in R$. Define $T_{n}:[0,1] \rightarrow R$ by $T_{n}(x)=\varphi\left(2^{n} x\right) ; T_{n}$ is a sawtooth curve with $2^{n}$ teeth. Clearly $\left\{T_{n} \mid n=1,2, \cdots\right\}$ is a uniformly bounded family of continuous functions which is not equicontinuous. If $T_{n} x \neq T_{n} y$, let us compute $\psi\left(T_{n}, x, y ; \alpha\right)$. If $\left(x, T_{n} x\right)$ and $\left(y, T_{n} y\right)$ lie on the same half of a tooth, then $\psi\left(T_{n}, x, y ; \alpha\right)=\alpha$. If $\left(x, T_{n} x\right)$ and $\left(y, T_{n} y\right)$ lie on different teeth, or on different halves of the same tooth, there is a $z$ lying between $x$ and $y$ such that $T_{n} z=T_{n} y$ and $\left(x, T_{n} x\right),\left(z, T_{n} z\right)$ lie on the same half of a tooth. Since $\psi\left(T_{n}, x, z ; \alpha\right)=\alpha$ and $T_{n} z=T_{n} y$, we see that $\psi\left(T_{n}, x, y ; \alpha\right)>\alpha$. So for any $x \neq y$ in $X, \psi(x, y ; \alpha) \geqq \alpha$, and the hypotheses of Theorem 1 are fulfilled by a family of continuous functions which is not equicontinuous.

We conclude by making some remarks on the following problem: Suppose $(X, d)$ is complete, $\left(Y, d^{\prime}\right)$ is a metric space, and $\mathscr{F}$ is a pointwisebounded family of maps from $X$ into $Y$ such that each $T_{\alpha} \in \mathscr{F}$ is continuous on a closed subset $S_{\alpha}$ of $X$. Can we conclude that the family $\mathscr{F}$ is uniformly bounded on a finite intersection $\bigcap_{k=1}^{n} S_{\alpha_{k}}$ ?

As in Theorem 1, the idea is to establish a contradiction by setting up some technical machinery. Assume that, if $\mathscr{F}$ were not uniformly bounded on any finite intersection of the $\left\{S_{\alpha}\right\}$, we could establish the following assertion: Let $x_{0} \in \bigcap_{\alpha} S_{\alpha}, p>0$. Given $x_{1}, \cdots, x_{n} \in X, T_{1}, \cdots, T_{n} \in \mathscr{F}$ (with $T_{k} \mid S_{k}$ continuous), $d\left(x_{0}, x_{k}\right)<p$, and given $M>0$, then we can find $T_{n+1} \in \mathscr{F}$ anci $x_{n+1} \in \bigcap_{k=1}^{n} S_{k}$ with $d\left(x_{0}, x_{n+1}\right)<p, d\left(x_{n}, x_{n+1}\right)<1 / 2^{n+1}$, $d^{\prime}\left(T_{n+1} x_{n+1}, T_{n+1} x_{0}\right)>M$ and $d^{\prime}\left(T_{k} x_{n}, T_{k} x_{n+1}\right)<1 / 2^{n+1}$ for $1 \leqq k \leqq n$. Such machinery leads to a contradiction in the same fashion as Theorem 1; the critical point here is that not only does $x_{n} \rightarrow x$, but for $k \geqq n+1$ we have $x_{k} \in S_{n}$ and since $\left\{x_{k} \mid k \geqq n+1\right\} \subseteq S_{n}$ and $S_{n}$ is closed, we can use the continuity of $T_{n}$ on $S_{n}$ to complete the proof.

General conditions on $\mathscr{F}$ and $\left\{S_{\alpha}\right\}$ are sufficiently involved as to limit their utility drastically. Although this theorem has been proved when $X$ is a complete metric space with unique segments, the sets $\left\{S_{\alpha}\right\}$ are convex and $\mathscr{F}$ consists of affine maps (this is done in [5]), these conditions are quite restrictive, and a theorem of this type for general $X,\left\{S_{\alpha}\right\}$, and $\mathscr{F}$ appears to be extremely difficult to obtain.

Two questions naturally present themselves in connection with this paper. First, is it possible to establish reasonable sufficient conditions on $\mathscr{F}$ and $\left\{S_{\alpha}\right\}$ as discussed previously? Second, is it possible to establish conditions for a pointwise-bounded family of continuous functions to be 
equicontinuous? Answers to these questions would be extremely interesting.

\section{BIBLIOGRAPHY}

1. A. Alexiewicz, On sequences of operations. I, Studia Math. 11 (1949), 1-30. MR $12,418$.

2. N. Dunford and J. Schwartz, Linear operators. I: General theory, Pure and Appl. Math., vol. 7, Interscience, New York and London, 1958. MR 22 \#8302.

3. V. Ptak, $A$ uniform boundedness theorem and mappings into spaces of operators, Studia Math. 31 (1968), 425-431. MR 38 \#4967.

4. J. Stein, Several theorems on boundedness and equicontinuity, Proc. Amer. Math. Soc. 26 (1971), 415-419.

5. —, Two uniform boundedness theorems, Pacific J. Math. (to appear).

Department of Mathematics, University of California, los Angeles, CaliFORNIA 90024 